\section{Kidney \\ Blood Pressure Research}

\title{
Clinicopathological Features and Outcomes of IgA Nephropathy with Hematuria and/ or Minimal Proteinuria
}

\author{
Min Tan, Wenge Li, Guming Zou, Cong Zhang, Jing Fang \\ Center of Nephrology, China-Japan Friendship Hospital, Health Ministry of China, Beijing, China
}

\section{Key Words}

IgA nephropathy $\bullet$ Proteinuria $•$ Clinical features $•$ Kidney pathology

\begin{abstract}
Background/Aims: Information regarding the clinical and histological prognostic factors of IgA nephropathy (IgAN) is mostly derived from patients in whom diagnostic renal biopsies were performed because their proteinuria levels were higher than 1-2 $\mathrm{g} / \mathrm{d}$. The clinicopathological features and outcomes of IgAN patients presenting with normal blood pressure, normal renal function, hematuria and minimal or no proteinuria are not well described. We therefore conducted a study of the clinicopathological features and outcomes in IgAN patients with these characteristics. Methods: The clinical, laboratory, and pathological manifestations and long-term outcomes of all IgAN patients with the above-mentioned characteristics were collected. The relationships between renal pathology, injury, long-term outcomes and clinical factors were studied, and the risk factors of IgAN were analyzed using multivariate logistic regression. Results: Of all of the renal biopsy cases, IgAN with the above features accounted for $8.9 \%$. Among these patients, $67.2 \%$ (253) showed simultaneous hematuria and proteinuria, $23.1 \%$ (87) showed only hematuria, and $9.7 \%$ (36) showed only proteinuria. Additionally, $33.8 \%$ (127) patients showed macroscopic hematuria and $65.1 \%(245)$ had a prodromal infection. Regarding renal pathological changes, $45.5 \%$ (171) of the patients were unexpectedly classified as Grade II to IV (Hass classification). Proteinuria at the time of renal biopsy was an independent predictor of more severe renal pathological injury. After a median followup of 75 months, 61 (16.2\%) patients experienced adverse events. Among these patients, $28(7.45 \%)$ exhibited hypertension, 22 (5.85\%) presented proteinuria levels $>1 \mathrm{~g} / 24 \mathrm{~h}$, and 11 (2.9\%) developed impaired renal function. Conclusions: Severe renal histological injury may be observed in some IgAN patients with benign clinical characteristics. Proteinuria is an independent predictor of severe renal pathological injury in IgAN patients with mild proteinuria. More severe pathological injury (> Grade II, Hass classification) are predictors of poor prognosis.
\end{abstract}




\section{Kidney \\ Blood Pressure Research}

Tan/Li/Zou/Zhang/Fang: IgAN with Benign Clinical Characteristics

\section{Introduction}

Immunoglobulin A nephropathy (IgAN), or Berger's disease, is the most common type of primary glomerulonephritis worldwide [1]. Although IgAN has been considered a benign condition for many years, a large number of cases eventually progress to renal failure [2-5].

Several clinical and histological parameters such as severe proteinuria [3, 6-8], arterial hypertension [3, 8], reduced renal function at diagnosis [7], and glomerular sclerosis or tubulointerstitial scarring at renal biopsy $[3,7,8]$ have been identified as independent risk factors for progression toward renal failure.

Nevertheless, information regarding these clinical and histological prognostic factors is mostly based on patients in whom diagnostic renal biopsies were performed due to proteinuria levels higher than 1-2 g/d [6, 8, 9-14]. Many studies reviewing the long-term prognosis of IgAN did not include patients with hematuria and minimal proteinuria $(<1.0$ $\mathrm{g} / \mathrm{d}$ ) at the time of diagnosis. According to studies performed in China and Japan, IgAN combined with hematuria and minimal proteinuria is generally a progressive disease, and few patients had a complete resolution of hematuria [15-19]. Limited studies have been conducted regarding the clinicopathological features and outcomes of patients with IgAN who present with normal blood pressure, normal renal function, hematuria and minimal or no proteinuria. We therefore conducted a retrospective analysis of IgAN patients with the above characteristics.

\section{Materials and Methods}

\section{Study population}

The study sample included 459 adult patients with biopsy-proven IgAN between January of 2000 and December of 2009 in the China-Japan Friendship Hospital in Beijing, China. These 459 patients accounted for $8.9 \%$ of all renal biopsy cases during the same period. The inclusion criteria comprised normal renal function (defined by an eGFR level $>60 \mathrm{ml} / \mathrm{min}$ per $1.73 \mathrm{~m}^{2}$ ), normal blood pressure (defined as systolic blood pressure $<140 \mathrm{mmHg}$ and /or diastolic blood pressure $<90 \mathrm{mmHg}$ without the use of antihypertensive drugs), and a proteinuria level $<1.0 \mathrm{~g} / 24 \mathrm{~h}$ (the mean of three 24 -hour proteinuria measurements before the kidney biopsy). Patients with Henoch-Schönlein purpura, liver disease, diabetes, systemic diseases, and any type of secondary IgAN were excluded.

\section{Ethics}

The research reported was conducted in accordance with the ethical standards established by the United States National Institute of Health.

\section{Data Collection}

Clinical and laboratory data recorded at biopsy included gender, age, medical history, presenting symptoms, medications, blood pressure, 24-hour urinary protein excretion, serum creatinine ( $\mathrm{SCr}$ ), estimated GFR (eGFR), serum IgA and serum uric acid (UA).

\section{Renal Biopsy}

All renal biopsy specimens were reviewed by a single pathologist blinded to the patient's clinical condition. The pathological diagnosis of IgAN was based on predominant mesangial IgA-containing immune complexes on immunofluorescence and electron microscopy. Renal biopsies, all of which contained at least ten glomeruli, were processed for light and immunofluorescence microscopy. Because the Oxford classification of IgAN is suitable for patients whose proteinuria is greater than $0.5 \mathrm{~g} / 24 \mathrm{~h}$, we chose the Hass classification to analyze our pathology data. Under light microscopy, biopsies were graded from I to $\mathrm{V}$ according to the Hass classification grades [20], as follows: Grade I, normal histology or mild increase in the mesangial matrix without segmental lesions; Grade II, focal and segmental glomerular sclerosis without glomerular hypercellularity or crescents; Grade III, focal (involving $\leq 50 \%$ of glomeruli present, 


\section{Kidney \\ Blood Pressure Research}

Table 1. Clinical Characteristics

\begin{tabular}{lc}
\hline & $\begin{array}{c}\text { Number (\%) } \\
\text { or Mean } \pm \text { SD }\end{array}$ \\
\hline Male gender (N [\%]) & $202(53.6)$ \\
Age, years (mean [SD]) & $27.4(8.7)$ \\
Pre-biopsy duration (mean [SD]) & $10.1(4.2)$ \\
Only hematuria (N [\%]) & $87(23.1)$ \\
Only proteinuria (N [\%]) & $36(9.7)$ \\
Hematuria and proteinuria (N [\%]) & $253(67.2)$ \\
Macroscopic hematuria (N [\%]) & $127(33.8)$ \\
prodromal infection (N [\%]) & $245(65.1)$ \\
\hline
\end{tabular}

\section{Kidney Blood Press Res 2015;40:200-206}

\begin{tabular}{l|l}
\hline DOI: $10.1159 / 000368495$ & (C) 2015 S. Karger AG, Basel
\end{tabular}

Published online: April 06, 2015

www.karger.com/kbr

Tan/Li/Zou/Zhang/Fang: IgAN with Benign Clinical Characteristics

Table 2. Laboratory data

\begin{tabular}{lc}
\hline & Mean \pm SD \\
\hline Systolic BP $(\mathrm{mmHg})$ & $116 \pm 60.7$ \\
Diastolic BP $(\mathrm{mmHg})$ & $70.6 \pm 33.5$ \\
SCr $(\mu \mathrm{mol} / \mathrm{L})$ & $83.4 \pm 41.7$ \\
eGFR $(\mathrm{ml} / \mathrm{min})$ & $92.8 \pm 28.3$ \\
Proteinuria $(\mathrm{g} / 24 \mathrm{~h})$ & $0.42 \pm 0.35$ \\
Serum UA $(\mathrm{mmol} / \mathrm{L})$ & $310.1 \pm 108.0$ \\
Serum $\mathrm{IgA}(\mathrm{g} / \mathrm{L})$ & $3.0 \pm 0.2$ \\
\hline
\end{tabular}

exclusive of globally sclerotic glomeruli) mesangial and/or endocapillary proliferative glomerulonephritis; Grade IV, diffuse (involving $>50 \%$ of glomeruli present, exclusive of globally sclerotic glomeruli) mesangial and/or endocapillary proliferative glomerulonephritis; Grade V, advanced chronic glomerulonephritis characterized by $\geq 40 \%$ globally sclerotic glomeruli and/or $\geq 40 \%$ interstitial fibrosis/tubular atrophy present in the cortical tissue, regardless of other histological features.

Follow-up for adverse events

Patients were evaluated in the clinic at a minimum of every 3 months. At each visit, the use of medications and laboratory data were recorded. Eighty-three patients were lost to follow-up within 12 months after the renal biopsy and were therefore excluded. We reviewed the clinical records of the remaining 376 patients. Adverse events included proteinuria ( $>1$ g per day) on two consecutive occasions, hypertension, (systolic blood pressure $\geq 140 \mathrm{~mm} \mathrm{Hg}$ or diastolic blood pressure $\geq 90 \mathrm{mmHg}$ ), and impaired renal function, defined as either an SCr level of $120 \mu \mathrm{mol} / \mathrm{L}$ or an SCr increase $>50 \%$.

\section{Statistical Analysis}

Quantitative variables with a normal distribution were expressed as the means and SDs and were compared using t tests. Qualitative variables were described by frequency distributions and analyzed by chi-squared tests. The clinical and laboratory factors affecting pathological damage were analyzed by multivariate logistic regression. All statistical analyses were performed using SPSS statistical software (version 12.0; Chicago, IL, USA).

\section{Results}

Baseline Clinical Characteristics

Of the 376 patients, 202 were males, and 174 were females (sex ratio 1.16:1). The mean age at entry into the study (baseline) was $(27.4 \pm 8.7)$ years. The mean time from disease onset to the time of the renal biopsy was 10.1 months ( 3 days to 15 years). Of all of the patients, 67.2\% (253) showed simultaneous hematuria and proteinuria, 23.1\% (87) showed only hematuria, and 9.7\% (36) showed only proteinuria. Additionally, 33.8\% (127) showed macroscopic hematuria, and $65.1 \%$ (245) had a prodromal infection. Upper respiratory tract infections were the most common, accounting for $69.6 \%$ of the cases; gastrointestinal infection accounted for $28.4 \%$, and other infections accounted for $2 \%$ of the cases (Table 1 ).

\section{Baseline laboratory data}

The patients' baseline laboratory data are shown in Table 2. All patients had normal blood pressure (BP) and renal function. The mean systolic blood pressure was $116 \mathrm{mmHg}$ (85-132 $\mathrm{mmHg}$ ), and the mean diastolic blood pressure was $70.6 \mathrm{mmHg}$ (55-83 $\mathrm{mmHg}$ ). The mean proteinuria level was $0.42 \mathrm{~g} / 24 \mathrm{~h}$, and $25.8 \%$ (97) of the patients had improved serum IgA levels. 


\section{Kidney Blood Pressure Research}

\section{Kidney Blood Press Res 2015;40:200-206}

DOI: 10.1159/000368495

Published online: April 06, 2015

C 2015 S. Karger AG, Basel

www.karger.com $/ \mathrm{kbr}$

Table 3. Analysis of the risk factors of pathological injury

\begin{tabular}{lccc}
\hline & $\begin{array}{c}\text { Group 1 } \\
\text { Hass I }\end{array}$ & $\begin{array}{c}\text { Group 2 } \\
\text { Hass II -Hass IV }\end{array}$ & P value \\
\hline Male gender (N [\%]) & $97(47.5)$ & $(105) 61.4$ & 0.052 \\
Age, years (mean [SD]) & $28.2(6.5)$ & $26.4(9.1)$ & 0.176 \\
Pre-biopsy duration (mean [SD]) & $9.8(1.4)$ & $10.5(3.2)$ & 0.280 \\
Macroscopic hematuria (N [\%]) & $72(35.1)$ & $55(32.2)$ & 0.135 \\
Prodromal infection (N [\%]) & $135(65.9)$ & $110(64.3)$ & 0.291 \\
Systolic BP (mmHg, mean [SD]) & $115(58.7)$ & $117(60.9)$ & 0.188 \\
Diastolic BP (mmHg, mean [SD]) & $71(34.2)$ & $70(33.8)$ & 0.211 \\
SCr ( $\mu$ mol/L, mean [SD]) & $80.5(40.7)$ & $86.3(40.2)$ & 0.576 \\
eGFR (ml/min, mean [SD]) & $91.5(31.2)$ & $94.4(30.5)$ & 0.125 \\
Proteinuria (g/24 h, mean [SD]) & $0.28(0.22)$ & $0.59(0.4)$ & 0.007 \\
Serum UA (mmol/L, mean [SD]) & $325.3(112)$ & $291.9(103)$ & 0.115 \\
Serum IgA (g/L, mean [SD]) & $3.3(0.3)$ & $2.6(0.5)$ & 0.101 \\
\hline OR=3.453, 95\% CI: 1.54 7.69, P=0.007; The unit of pre-biopsy & duration is \\
months & \multicolumn{3}{l}{} \\
\hline
\end{tabular}

Table 4. Correlation analysis of proteinuria and pathological injury

\begin{tabular}{lccc}
\hline The degree of & $\begin{array}{c}\text { simple } \\
\text { hematuria }\end{array}$ & proteinuria $(\mathrm{g} / 24 \mathrm{~h})$ \\
\hline pathological injury & & $0.15-0.50$ & $0.51-1.0$ \\
\hline Hass I (N [\%]) & $64(73.6)$ & $85(58.6)$ & $54(37.5)$ \\
Hass II (N [\%]) & $5(5.7)$ & $12(8.3)$ & $22(15.3)$ \\
Hass III (N [\%]) & $18(20.7)$ & $46(31.7)$ & $62(43.0)$ \\
Hass IV (N [\%]) & 0 & $2(1.4)$ & $6(4.2)$ \\
\hline $\mathrm{X}^{2}=11.32, \mathrm{p}=0.004$ & & & \\
\hline
\end{tabular}

Histological findings

The Hass grade distribution of the 376 patients was as follows: Grade I, 205 (54.5\%); Grade II, 28 (7.5\%); Grade III, 132 (35.1\%); and Grade IV, 11 (2.9\%). No Grade V disease was found. Of all of the patients, 135 (35.9\%) patients had varying degrees of sclerotic glomeruli, $140(37.3 \%)$ patients had crescents, $105(27.8 \%)$ patients had focal interstitial fibrosis, 106 $(29.5 \%)$ patients had focal tubular atrophy, and 269 (74.9\%) patients had varying degrees of vascular lesions.

\section{Major Risk Factor Analysis}

Patients with a histological Hass grade of I were classified as group 1. Patients with histological Hass grades of II, III and IV were classified as group 2. According to the analysis, the proteinuria level in group 2 was much higher than that in group 1 . However, no differences in gender, age, course of illness, macroscopic hematuria, prodromal infection, blood pressure, eGFR, serum UA and serum IgA were found between the groups. In the logistic regression analysis, only proteinuria was correlated with severe pathological injury (Table 3). Additionally, the risk of obvious pathological injury increased along with increased urinary protein levels (Table 4).

\section{Follow-up and treatment}

The median follow-up was 75 months (range=16-170 months). Patients with proteinuria levels $>0.3 \mathrm{~g} / 24 \mathrm{~h}$ received treatment with either angiotensin-converting enzyme inhibitors (ACEIs) or angiotensin receptor blockers (ARBs). A total of 231 (61.4\%) patients 


\section{Kidney Blood Pressure Research}

Table 5. Analysis of the risk factors of adverse events

\begin{tabular}{lccc}
\hline & $\begin{array}{c}\text { Developed } \\
\text { adverse events }\end{array}$ & $\begin{array}{c}\text { No adverse } \\
\text { events }\end{array}$ & \\
\cline { 2 - 4 } & $\mathrm{n}=61$ & $\mathrm{n}=315$ & P value \\
\hline Male gender (N [\%]) & $37(60.7)$ & $165(52.4)$ & 0.131 \\
Age, years (mean [SD]) & $28.0(5.7)$ & $26.6(4.5)$ & 0.570 \\
Course of illness (mean [SD]) & $9.1(1.9)$ & $11.2(2.2)$ & 0.350 \\
Proteinuria 0.50-1.0 g/d (N [\%]) & $42(68.9)$ & $102(32.4)$ & 0.002 \\
prodromal infection (N [\%]) & $23(37.7)$ & $222(70.5)$ & 0.052 \\
$>$ Grade 2 histology (N [\%]) & $59(96.7)$ & $112(35.6)$ & $<0.001$ \\
\hline
\end{tabular}

started treatment with ACEIs or ARBs at baseline due to proteinuria. Another 59 patients started ACEI/ARB treatment during follow-up due to hypertension (11 patients), increased proteinuria (31 patients), or hypertension plus increased proteinuria (17 patients). During the follow-up, the proteinuria levels of $22(5.9 \%)$ patients increased to values $>1 \mathrm{~g} / \mathrm{d}$ despite the use of ACEIs or ARBs. At the end of follow-up, 11 (2.9\%) patients developed impaired renal function. Most patients who experienced adverse events at the end of follow-up had baseline proteinuria levels $>0.5 \mathrm{~g} / 24 \mathrm{~h}$ or had severe pathological injury (Table 5). Proteinuria was resolved in only 4 patients, and 10 patients had a complete resolution of hematuria.

\section{Discussion}

IgAN is the most common primary glomerular disease worldwide [1]. The histological features and clinical course of IgAN are highly variable [21]. Because a majority of IgAN diagnoses result from renal biopsies performed in patients presenting with proteinuria levels higher than 1-2 $\mathrm{g} / 24 \mathrm{~h}$ or impaired renal function, information regarding the clinicopathological features and outcomes of IgAN patients presenting with hematuria and/or minimal proteinuria is scarce. In our study of 376 patients with benign clinical characteristics at the time of renal biopsy, 67.2\% (253) showed simultaneous hematuria and proteinuria, 23.1\% (87) showed only hematuria, and 9.7\% (36) showed only proteinuria. Additionally, 33.8\% (127) showed macroscopic hematuria, and 65.1\% (245) had prodromal infections. Liu et al. found that focal and/or segmental glomerulosclerosis (FSGS) played an important role in patients with IgA nephropathy presenting with isolated hematuria [22]. In our study, approximately half of the patients presented with obvious pathological injury (Hass grade II IV). Approximately $1 / 3$ of the patients presented with varying degrees of sclerotic glomeruli and interstitial fibrosis, suggesting that pathological injury is not benign in patients with benign clinical characteristics.

High-grade proteinuria is a risk factor for poor outcomes [23, 24]. Not enough evidence is available to assess whether mild proteinuria is also a risk factor for poor outcomes. In the multivariate analysis, proteinuria was an independent risk factor for pathological injury in patients with benign clinical characteristics. Compared with patients with simple hematuria, the risk of more severe pathological injury (Haas grade II or above) was 3.5 times higher in patients with proteinuria. The risk of more severe pathological injury also increases with increased urine protein levels; approximately $50 \%$ of patients with higher proteinuria levels $(0.5 \mathrm{~g} / 24 \mathrm{~h}$ to $1.0 \mathrm{~g} / 24 \mathrm{~h})$ had more severe pathological injury. Therefore, reducing proteinuria levels as much as possible is critical, even in patients with proteinuria levels less than $1.0 \mathrm{~g} / 24 \mathrm{~h}$.

According to studies conducted in China and Japan [15-19] on patients with benign clinical characteristics at the time of renal biopsy (normal renal function, normal BP, and proteinuria $=0.4 \mathrm{~g} / 24 \mathrm{~h}$ or less), $33 \%-46 \%$ develop proteinuria levels of $0.5-1.0 \mathrm{~g} /$ 


\section{Kidney \\ Blood Pressure Research}

$24 \mathrm{~h}, 26 \%-38 \%$ develop hypertension, and 7\%-24\% exhibit impaired renal function after a median follow-up of 7-11 years. These results suggest that IgAN is a generally progressive disease, even in patients presenting with more benign clinical characteristics. However, Gutiérrez et al. found that the long-term prognosis is excellent for Caucasian patients with IgAN presenting with minor urinary abnormalities and normal renal function [25]. The longterm prognosis of IgAN with benign clinical characteristics differs in European and Asian patients. Genetic differences in these populations may be associated with variations in the susceptibility to and prognosis of IgAN [26-27]. Our study analyzed the clinicopathological features and outcomes of 376 patients with normal renal function, normal BP, and proteinuria levels of $1.0 \mathrm{~g} / 24 \mathrm{~h}$ or less. After a median follow-up of 75 months, 23 (5.9\%) patients had proteinuria levels that increased to values $>1 \mathrm{~g} / \mathrm{d}$ despite the use of ACEIs or ARBs, 11 (2.9\%) patients developed impaired renal function, and $28(7.4 \%)$ patients developed hypertension. Most adverse events occurred in patients with baseline proteinuria levels of 0.5-1.0 g/24 h. Baseline proteinuria levels of $>0.5 \mathrm{~g} / 24 \mathrm{~h}$ and more severe pathological injury significantly influenced the probability of adverse events. The prognosis of IgAN patients with benign clinical characteristics in our center is slightly better than that previously reported in China and Japan. This may be a result of using ACEIs or ARBs in the early stage of IgAN. More research should be conducted to determine the effect of ACEIs or ARBs on IgAN patients with benign clinical characteristics.

\section{Conclusion}

Severe renal histological injury may be observed in some IgAN patients with benign clinical characteristics. Proteinuria is an independent predictor of severe renal pathological injury in IgAN patients with benign clinical characteristics. Proteinuria levels $>0.5 \mathrm{~g} / 24$ $\mathrm{h}$ and severe pathological injury ( $>$ Grade II, Hass classification) are predictors of a poor prognosis. IgAN patients with mild proteinuria should undergo a renal biopsy.

\section{Disclosure Statement}

The authors report no conflicts of interest.

\section{Acknowldegements}

This work was supported by the grant of National Clinical Research Center for Kidney Diseases (No. 2013BAI09B05) and Beijing Natural Science Foundation (No.7152127).

\section{References}

1 Julian BA, Waldo FB, Rifai A, Mestecky J: IgA nephropathy, the most common glomerulonephritis worldwide. A neglected disease in the United States? Am J Med 1988;84:129-132.

2 D’Amico G, Colasanti G, Barbiano di Belgioioso G, Fellin G, Ragni A, Egidi F, Radaelli L, Fogazzi G, Ponticelli C, Minetti L: Long-term follow-up of IgA mesangial nephropathy: clinico-histological study in 374 patients. Semin Nephrol 1987;7:355-358.

3 Radford MG Jr, Donadio JV Jr, Bergstralh EJ, Grande JP: Predicting renal outcome in IgA nephropathy. J Am Soc Nephrol 1997;8:199-207.

4 Ibels LS, Gyory AZ: IgA nephropathy: analysis of the natural history, important factors in the progression of renal disease, and a review of the literature. Medicine (Baltimore) 1994;73:79-102. 


\section{Kidney \\ Blood Pressure Research}

Kidney Blood Press Res 2015;40:200-206

\begin{tabular}{l|l}
\hline DOI: $10.1159 / 000368495$ & C 2015 S. Karger AG, Basel
\end{tabular}

Published online: April 06, 2015

www.karger.com/kbr

5 Hogg RJ, Silva FG, Wyatt RJ, Reisch JS, Argyle JC, Savino DA: Prognostic indicators in children with IgA nephropathy - report of the Southwest Pediatric Nephrology Study Group. Pediatr Nephrol 1994;8:15-20. Bartosik LP, Lajoie G, Sugar L,Cattran DC: Predicting progression in IgA nephropathy. Am J Kidney Dis 2001;38:728-735.

7 Frimat L, Briancon S, Hestin D, Aymard B, Renoult E, Huu TL, Kessler M: IgA nephropathy: Prognostic classification of end-stage renal failure. Nephrol Dial Transplant 1997;12:2569-2575.

8 Alamartine E, Sabatier JC, Guerin C, Berliet JM, Berthoux F: Prognostic factors in mesangial IgA glomerulonephritis: An extensive study with univariate and multivariate analyses. Am J Kidney Dis 1991;18:12-19.

9 D'Amico G: Natural history of idiopathic IgA nephropathy: Role of clinical and histological prognostic factors. Am J Kidney Dis 2000;36:227-237.

10 Berthoux F, Mohey H, Laurent B, Mariat C, Afiani A, Thibaudin L: Predicting the risk for dialysis or death in IgA nephropathy. J Am Soc Nephrol 2011;22:752-761.

11 Reich HN, Troyanov S, Scholey JW, Cattran DC; Toronto Glomerulonephritis Registry: Remission of proteinuria improves prognosis in IgA nephropathy. J Am Soc Nephrol 2007;18:3177-3183.

12 Barratt J, Feehally J: IgA nephropathy. J Am Soc Nephrol 2005;16:2088-2097.

13 Donadio JV, Bergstralh EJ, Grande JP, Rademcher DM: Proteinuria patterns and their association with subsequent end-stage renal disease in IgA nephropathy. Nephrol Dial Transplant 2002;17:1197-1203.

14 Coppo R, D’Amico G: Factors predicting progression of IgA nephropathies. J Nephrol 2005;18:503-512.

15 Lai FM, Szeto CC, Choi PC, Li PK, Chan AW, Tang NL, Lui SF, Wang AY, To KF: Characterization of early IgA nephropathy. Am J Kidney Dis 2000;36:703-708.

16 Szeto CC, Lai FM, To KF, Wong TY, Chow KM, Choi PC, Lui SF, Li PK: The natural history of immunoglobulin a nephropathy among patients with hematuria and minimal proteinnuria. Am J Med 2001;10:434-437.

17 Li PK, Ho KK, Szeto CC, Yu L, Lai FM: Prognostic indicators of IgA nephropathy in the Chinese - clinical and pathological perspectives. Nephrol Dial Transplant 2002;17:64-69.

18 Shen P, He L, Huang D: Clinical course and prognostic factors of clinical early IgA nephropathy. Neth J Med 2008;66:242-247.

19 Koyama A, Igarashi M, Kobayashi M: Research Group on Progressive Renal Diseases:Natural history and risk factors for immunoglobulin A nephropathy in Japan. Am J Kidney Dis 1997;29:526-532.

20 Hass M: Histologic subclassification of IgA nephropathy: a clinicopathologic study of 244 cases. Am J Kidney Dis 1997;29:829-842.

21 Coppo R, Cattran D, Roberts Ian SD, Troganov S, Camilla R, Cook T, Feenally J: The new oxford clinicopathological classification of IgA nephropathy. Prilozi 2010;31:241-248.

22 Liu H, Peng Y, Liu H, Liu Y, Yuan S, Liu F, Yang D, Chen X, He L, Fu M, Shao J, Yang L: Renal biopsy findings of patients presenting with isolated hematuria: disease associations. Am J Nephrol 2012;36:377-385.

23 Hunley TE, Kon V: IgA nephropathy. Curr Opin Pediatr 1999;11:152-157.

24 Mera J, Uchida S, Nagase M: Clinicopathologic study on prognostic markers in IgA nephropathy. Nephron 2000;84:148-157.

25 Gutiérrez E, Zamora I, Ballarín JA, Arce Y, Jiménez S, Quereda C, Olea T, Martínez-Ara J, Segarra A, Bernis C, García A, Goicoechea M, García de Vinuesa S, Rojas-Rivera J, Praga M; Grupo de Estudio de Enfermedades Glomerulares de la Sociedad Española de Nefrología (GLOSEN): Long-term outcomes of IgA nephropathy presenting with minimal or no proteinuria. J Am Soc Nephrol 2012;23:1753-1760.

26 Feehally J, Farrall M, Boland A, Gale DP, Gut I, Heath S, Kumar A, Peden JF, Maxwell PH, Morris DL, Padmanabhan S, Vyse TJ, Zawadzka A, Rees AJ, Lathrop M, Ratcliffe PJ: HLA has strongest association with IgA nephropathy in genome-wide analysis. J Am Soc Nephrol 2010;21:1791-1797.

27 Yu XQ, Li M, Zhang H, Low HQ,Wei X, Wang JQ, Sun LD, Sim KS, Li Y, Foo JN, Wang W, Li ZJ, Yin XY, Tang XQ, Fan L, Chen J, Li RS,Wan JX, Liu ZS, Lou TQ, Zhu L, Huang XJ, Zhang XJ, Liu ZH, Liu JJ: A genome-wide association study in Han Chinese identifies multiple susceptibility loci for IgA nephropathy. Nat Genet 2012;44:178-182. 